\title{
18. MAGNETIC PROPERTIES OF SEDIMENTS FROM HOLE 503A ${ }^{1}$
}

\author{
E. A. Hailwood, Department of Oceanography, University of Southampton, Southampton, United Kingdom \\ and \\ A. I. Rees, Institute of Oceanographic Sciences, Wormley, United Kingdom
}

\section{INTRODUCTION}

Measurements were made of the magnetic properties of 13 sediment samples from cores spanning the entire depth of Hole 503A. The principal aim was to make a preliminary assessment of the magnetic fabric of material obtained from hydraulic piston coring (HPC) which, though considerably bioturbated, might retain substantial traces of any depositional alignment of magnetic grains.

Earlier measurements on Deep Sea Drilling Project cores (Rees, 1971; Rees and Frederick, 1974; Hailwood and Sayre, 1979) suggested that the improved HPC sampling technique should, other things being equal, provide good magnetic fabric information. The Hole 503A sediments were known from shipboard measurements to possess comparatively strong stable remanence and therefore seemed likely subjects for this assessment.

\section{METHODS}

Before magnetic fabric measurement, the natural remanent magnetization (NRM) of each sample was measured with a cryogenic magnetometer, and its behavior under alternating field (AF) demagnetization was recorded. This procedure provided a sample-by-sample comparison of remanence and anisotropy of magnetic susceptibility. We also hoped to obtain a magnetic reference azimuth. The mean susceptibility $(\bar{K})$ of each specimen was measured using a standard acbridge technique, and susceptibility anisotropy measurements were attempted with a standard low-field torsion magnetometer (King and Rees, 1962) at 150-Oe RMS (Table 1).

With three exceptions, NRM intensities were in the range $2.9<J_{o}<9.9 \times 10^{-6}$ gauss. All were stable under AF demagnetization up to 200 to 600 -Oe peak. All NRM directions were near horizontal, which was expected for the latitude of deposition.

All specimens except two had mean susceptibilities in the range $40<\bar{K}<118 \times 10^{-6} \mathrm{emu}$. Koenigsberger ratios for all specimens except one were also closely grouped in the range $1.0<Q_{o}<3.7$.

These results suggest that the sediments have moderately strong magnetization, probably caused by singledomain magnetite grains. There was no obvious major effect from the substantial bioturbation. It was, therefore, surprising to find little susceptibility anisotropy. The susceptibility anisotropy parameter, $h$, an analog of $Q_{o}$, is commonly of the order 0.1 for sediments with

\footnotetext{
${ }^{1}$ Prell, W. L., Gardner, J. V., et al., Init. Repts. DSDP, 68: Washington (U.S. Govt. Printing Office).
}

detrital magnetism; in these sediments it was generally much less than 0.01 . The magnitudes of $h$ were not far above the noise level of the instrument.

The maximum- and minimum-susceptibility axes of all measurable specimens, plotted relative to north as indicated by NRM, are shown in Figure 1. Some grouping is evident despite the closeness to the instrumental noise level-maxima are clustered around a north-south horizontal axis, and minima are clustered loosely about an east-west axis. This combines with the observed high and variable values of the parameter $q$ (Table 1) to suggest systematic deformation by east-west compression (Graham, 1966).

But the most interesting aspect of the magnetic fabric is its weakness. We do not know of any other comparable case in which a magnetite-bearing sediment has comparatively so little susceptibility anisotropy.

The most likely explanation of the remanence caused by single domains implies individual magnetic particles whose remanence is caused by their shape anisotropies. If this is true, the magnetized particles cannot have been individually and physically aligned by the field during deposition, or a susceptibility anisotropy would accompany the remanence. The shapes of the single domains must be randomly oriented for there to be no such anisotropy present.

We suggest two possible mechanisms. Both depend on the magnetic particles being compound and made up of noninteracting single-domain grains randomly oriented in a nonmagnetic matrix. In the first mechanism, the compound grains would be formed before deposition, and the remanent magnetization would be depositional; in the second, the compound grains would be formed by alteration after deposition, and magnetization would be a chemical remanent magnetization (CRM).

Professor M. S. N. Carpenter of the Institute of Oceanographic Sciences has examined a few grains of a magnetic separate taken from the material trimmed from one of our specimens. His observations suggest that the magnetization may be associated with clouds of submicroscopic inclusions in grains of altered ferromagnesian minerals, probably originally derived from basic igneous rocks.

This suggests that one of our explanations may well be on the right lines. Either seems quantitatively credible: The best chance of distinguishing between them seems likely to come from a careful mineralogical study of the nature and origin of the magnetic fraction. 
Table 1. Magnetic properties of specimens from Hole 503A.

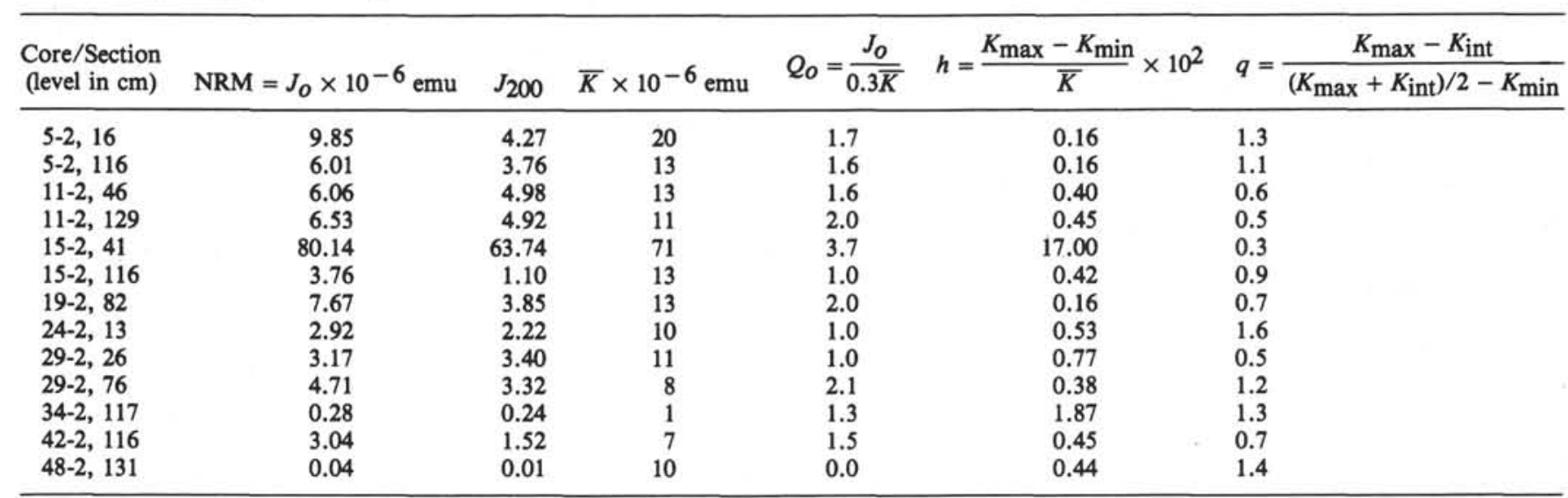

Note: All magnitudes are quoted in emu.

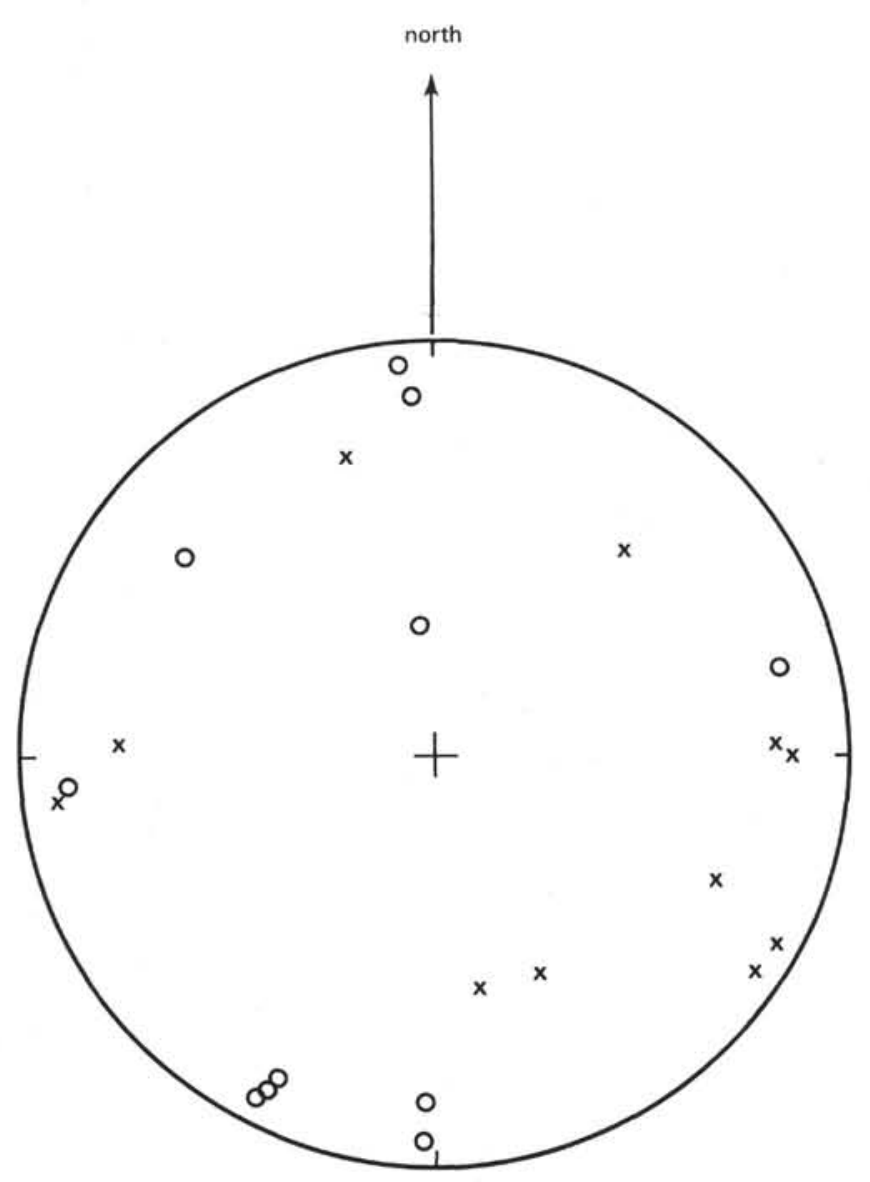

Figure 1. Principal axes of susceptibility relative to north; estimated from remanence (All measurable specimens; $O=$ maximum susceptibility; $x=$ minimum susceptibility; stereo [Wulff] net, lower hemisphere.)

\section{ACKNOWLEDGMENTS}

We are grateful to N. Hamilton, R. F. King, and W. H. Owens for reviewing our manuscript.

\section{REFERENCES}

Graham, J. W., 1966. Significance of magnetic anisotropy in Appalachian sedimentary rocks. In Steinhart, J. S., and Smith, T. J. (Eds), The Earth Beneath the Continents. American Geophysical Union Monograph 10: Washington (American Geophysical Union), pp. 627-648.

Hailwood, E. A., and Sayre, W. O., 1979. Magnetic anisotropy and sediment transport directions in North Atlantic Early Cretaceous black shales and Eocene mudstones cored on DSDP Leg 48. In Montadert, L., and Roberts, D. G., et al., Init. Repts. DSDP, 48: Washington (U.S. Govt. Printing Office), 909-918.

King, R. F., and Rees, A. I., 1962. The measurement of the anisotropy of magnetic susceptibility of rocks by the torque method. $J$. Geophys. Res., 67:1565-1572.

Rees, A. I., 1971. The magnetic anisotropy of samples from the Deep Sea Drilling Project, Leg 1, Orange, Texas to Hoboken, N. J. Mar. Geol., 11:M16-M23.

Rees, A. I., and Frederick, D., 1974. The magnetic fabric of samples from the Deep Sea Drilling Project, Legs I-VI. J. Sediment. Petrol., 44:655-662. 